\title{
The overlap syndrome of asthma and COPD: what are its features and how important is it?
}

\author{
P G Gibson, ${ }^{1,2}$ J L Simpson ${ }^{1}$
}

${ }^{1}$ Centre for Asthma and Respiratory Diseases, University of Newcastle, Newcastle, Australia; ${ }^{2}$ Department of Respiratory and Sleep Medicine, John Hunter Hospital, Newcastle, Australia

Correspondence to: Professor P Gibson, Department of Respiratory and Sleep Medicine, Level 3 HMRI, John Hunter Hospital, Locked Bag 1 , Hunter Mail Centre, Newcastle, NSW Australia 2310; peter.gibson@hnehealth.nsw. gov.au

Received 14 November 2008 Accepted 23 April 2009

\section{ABSTRACT}

There is a need to re-evaluate the concept of asthma and chronic obstructive pulmonary disease (COPD) as separate conditions, and to consider situations when they may coexist, or when one condition may evolve into the other. Epidemiological studies show that in older people with obstructive airway disease, as many as half or more may have overlapping diagnoses of asthma and COPD (overlap syndrome). These people are typically excluded from current therapy trials, which limit the generalisability of these trials, and this presents a problem for evidencebased guidelines for obstructive airway diseases. Studying overlap syndrome may shed light on the mechanisms of COPD development. Overlap syndrome is recognised by the coexistence of increased variability of airflow in a patient with incompletely reversible airway obstruction. Patients typically have inflammatory features that resemble COPD, with increased airway neutrophilia, as well as features of airway wall remodelling. Overlap syndrome can develop when there is accelerated decline in lung function, or incomplete lung growth, or both. The risk factors for these events are shared, such that increasing age, bronchial hyper-responsiveness, tobacco smoke exposure, asthma and lower respiratory infections/ exacerbations are significant risk factors for both incomplete lung growth and accelerated loss of lung function. Studying these events may offer new insights into the mechanisms and treatment of obstructive airway diseases.

Asthma and chronic obstructive pulmonary disease (COPD) are the most common obstructive airway diseases in our community. Asthma is recognised as an allergic disease that develops in childhood, characterised physiologically by reversible airflow obstruction, and has an episodic course with a generally favourable prognosis, responding well to anti-inflammatory treatment. In contrast, COPD is typically caused by tobacco smoking, develops in mid to later life and is characterised by incompletely reversible airflow limitation that results in a progressive decline in lung function leading to premature death. While these are useful descriptions, they are limited because they do not fully depict the spectrum of obstructive airway disease that is seen in clinical practice. In particular, now that accelerated decline in lung function is recognised to occur in asthma, especially in those with asthma who smoke, ${ }^{1}$ and COPD is increasingly considered to be a treatment-responsive disease, there is a need to re-evaluate the concept of asthma and COPD as separate conditions, and to consider situations when they may coexist, or when one condition may evolve into the other. These are circumstances where asthma and COPD can overlap, and this review will examine these issues.

\section{DEFINITIONS}

The accepted definitions for the distinct obstructive airway diseases and their component syndromes are described in table 1 . When a patient exhibits features of more than one condition, then they have an overlap syndrome. This review will address the overlap between asthma and COPD.

The current descriptions of asthma and COPD have been simplified into patterns of abnormal airway physiology (fig 1) which, in conjunction with symptoms, can be used to facilitate clinical recognition. There is a need to broaden these descriptions to accommodate the common clinical reality of people who fit the criteria for more than one condition. ${ }^{2}$ The American Thoracic Society 1995 COPD guidelines (fig 2) ) $^{3}$ defined asthma, chronic bronchitis, emphysema, COPD and airflow obstruction, and identified 11 distinct syndromes. Overlap between two or more conditions made up 6 of these 11 syndromes. Further guideline development in COPD has placed more emphasis on recognising COPD as a disease where incomplete reversibility of airflow obstruction is the defining characteristic. This is useful since it allows easier recognition of obstructive airway diseases in general, and COPD in particular. However, the potential for overlap of the individual obstructive airway disease syndromes has received less attention.

A recent study of the overlap in obstructive airway diseases using data from large population studies $^{4}$ found that $17 \%$ and $19 \%$, respectively, of patients had more than one condition present. With increasing age, there was a greater increase in the proportion of patients with obstructive lung disease who had overlapping diagnoses (fig 3). In older patients, a combined syndrome of asthma and COPD was the most common situation, as now confirmed using objective testing. ${ }^{5}$ Fewer than $20 \%$ of older patients have the classical phenotypes of emphysema alone or chronic bronchitis alone.

\section{WHY IS IT IMPORTANT?}

There are several reasons why the overlap syndrome is important. First, patients with overlapping asthma and COPD are excluded from clinical trials of treatment. This means that for an increasing proportion of older patients with obstructive lung disease, the data on efficacy of treatment may not be relevant. The clearest example of this comes from the studies on the efficacy of inhaled corticosteroids in asthma. These studies typically exclude smokers with asthma 
Table 1 Definition of obstructive airway syndromes

\begin{tabular}{|c|c|}
\hline Syndrome & Definition \\
\hline \multirow[t]{2}{*}{ Asthma } & Episodic respiratory symptoms \\
\hline & $\begin{array}{l}\text { Variable airflow obstruction occurring } \\
\text { spontaneously, with treatment or after } \\
\text { provocation }\end{array}$ \\
\hline COPD & Incompletely reversible airflow obstruction \\
\hline Overlap syndrome & $\begin{array}{l}\text { Asthma and COPD_-that is, symptoms of } \\
\text { increased variability of airflow and } \\
\text { incompletely reversible airflow obstruction }\end{array}$ \\
\hline Chronic bronchitis & $\begin{array}{l}\text { Symptomatic mucus hypersecretion with } \\
\text { cough and sputum daily for at least } \\
3 \text { months over } 2 \text { years }\end{array}$ \\
\hline Emphysema & Abnormal airspace enlargement \\
\hline \multirow[t]{3}{*}{ Variable airflow obstruction } & $\begin{array}{l}\text { Increased diurnal variability of peak flow: } \\
\text { maximum-minimum/average }>10 \%\end{array}$ \\
\hline & $\begin{array}{l}\text { Increased response to bronchodilator: }> \\
200 \mathrm{ml} \mathrm{FEV}{ }_{1} \text { and }>12 \% \text { baseline }\end{array}$ \\
\hline & $\begin{array}{l}\text { Increased airway responsiveness: } \\
\text { provocation dose or concentration } \\
<\text { normal }\end{array}$ \\
\hline $\begin{array}{l}\text { Incompletely reversible airflow } \\
\text { obstruction }\end{array}$ & $\begin{array}{l}\text { Postbronchodilator } \mathrm{FEV}_{1}<80 \% \text { predicted } \\
\text { and } \mathrm{FEV}_{1} / \mathrm{FVC}<70 \%\end{array}$ \\
\hline Bronchodilator responsiveness & $\begin{array}{l}\text { Improvement in } \mathrm{FEV}_{1}>15 \% \text { and } 400 \mathrm{ml} \\
\text { after a therapeutic dose of inhaled rapid } \\
\text { acting } \beta_{2} \text {-agonist }\end{array}$ \\
\hline Airway hyper-responsiveness & $\begin{array}{l}\text { Significant fall in } \mathrm{FEV}_{1} \text { from a stable } \\
\text { baseline after inhalation of bronchial } \\
\text { provocation stimulus occurring at a } \\
\text { stimulus dose less than required to induce } \\
\text { a significant change in } \mathrm{FEV}_{1} \text { in healthy } \\
\text { controls. }\end{array}$ \\
\hline
\end{tabular}

COPD, chronic obstructive pulmonary disease; $\mathrm{FEV}_{1}$, forced expiratory volume in $1 \mathrm{~s}$; FVC, forced vital capacity.

because of the difficulty in separating asthma from COPD in smokers with obstructive lung disease. However, up to $30 \%$ of people with asthma are smokers, and this means a substantial proportion of the population are excluded from randomised controlled trials. Extrapolation of the efficacy results for corticosteroids in non-smokers to smokers with asthma is flawed. Smokers with asthma have a relative corticosteroid resistance such that corticosteroids are much less efficacious in

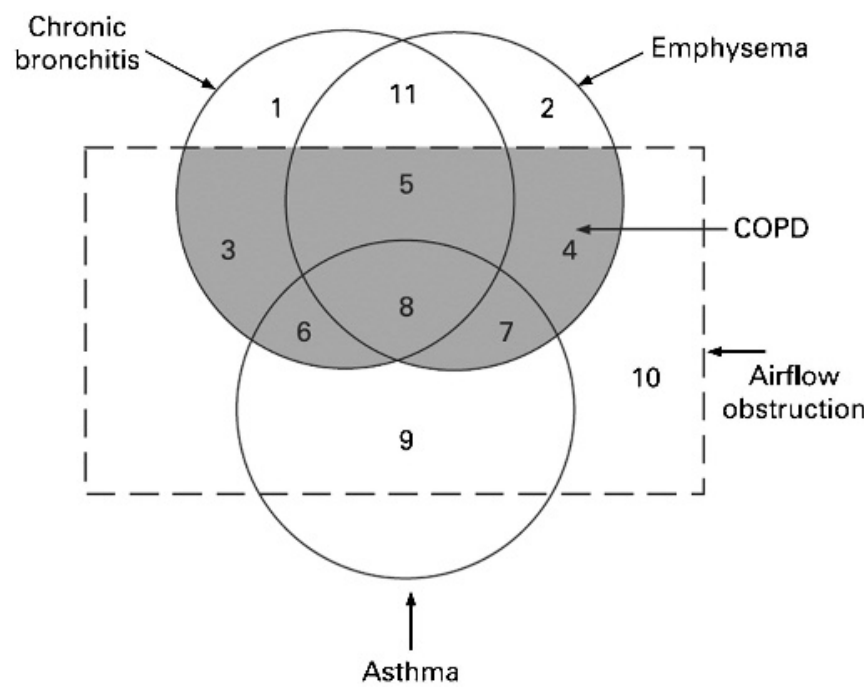

Figure 2 Non-proportional Venn diagram showing the number of overlapping conditions in patients with asthma, emphysema and chronic bronchitis (reproduced with permission from the American Journal of Respiratory and Critical Care Medicine). COPD, chronic obstructive pulmonary disease.

smokers with asthma than in non-smokers with asthma. ${ }^{6}$ This emphasises the need to study drug efficacy in relevant clinical populations, and the necessity to include overlap syndrome in drug evaluation programmes.

Secondly, clinicians are confused as to how and if they should differentiate asthma from COPD. In a study of the use of diagnostic labels for obstructive airway, many clinicians felt the need to extend the diagnostic label beyond asthma to indicate the presence of other clinical features, using additional terms such as asthma with chronic bronchitis, chronic obstructive bronchitis, asthma with permanent obstruction and COPD with a reversible component. The authors observed variation in the use of diagnostic labels for obstructive airway diseases, nonsystematic use of current terms and uncertainty surrounding a
Figure 1 Physiological patterns of airflow obstruction, expressed as forced expiratory volume in $1 \mathrm{~s}\left(\mathrm{FEV}_{1}\right)$, percentage predicted. Reversible AO, reversible airflow obstruction with improvement in $\mathrm{FEV}_{1}$ after bronchodilator; irreversible $\mathrm{AO}$, incompletely reversible airflow obstruction, postbronchodilator $\mathrm{FEV}_{1}$ is $<80 \%$; irreversible $\mathrm{A} 0+\mathrm{BDR}$, incompletely reversible airflow obstruction with significant bronchodilator responsiveness (BDR) irreversible $\mathrm{A} 0+\mathrm{BHR}$, incompletely reversible airflow obstruction with significant bronchial hyperresponsiveness with fall in $\mathrm{FEV}_{1}$ after bronchoconstrictor. The label 'asthma' can be applied to reversible $\mathrm{AO}$, irreversible $\mathrm{AO}+\mathrm{BDR}$ and irreversible $A 0+B H R$. Chronic obstructive pulmonary disease (COPD) can be applied to each of the conditions with irreversible $\mathrm{AO}+\mathrm{BHR}$. Overlap syndrome is present in irreversible $\mathrm{AO}+\mathrm{BDR}$ and irreversible $\mathrm{AO}+\mathrm{BHR}$.

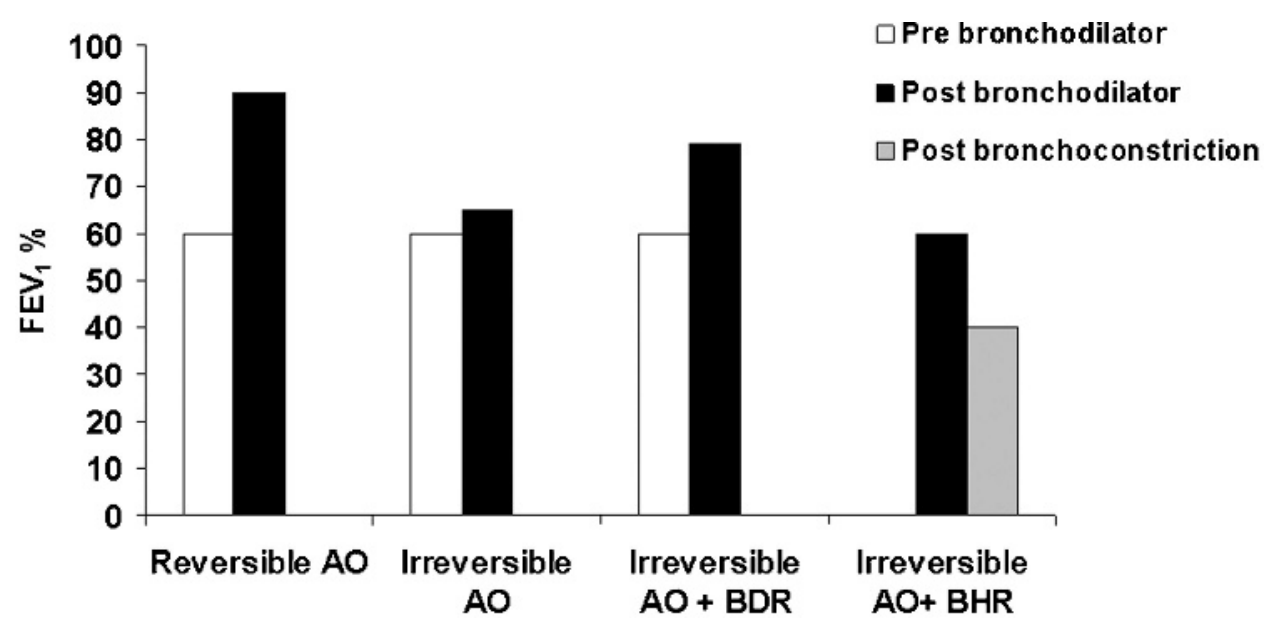


Figure 3 Percentage of adults (by gender) with airflow obstruction who have an overlap syndrome with increasing age. Males are shown in the black bars and females in the white bars. Data from Soriano et al. ${ }^{4}$

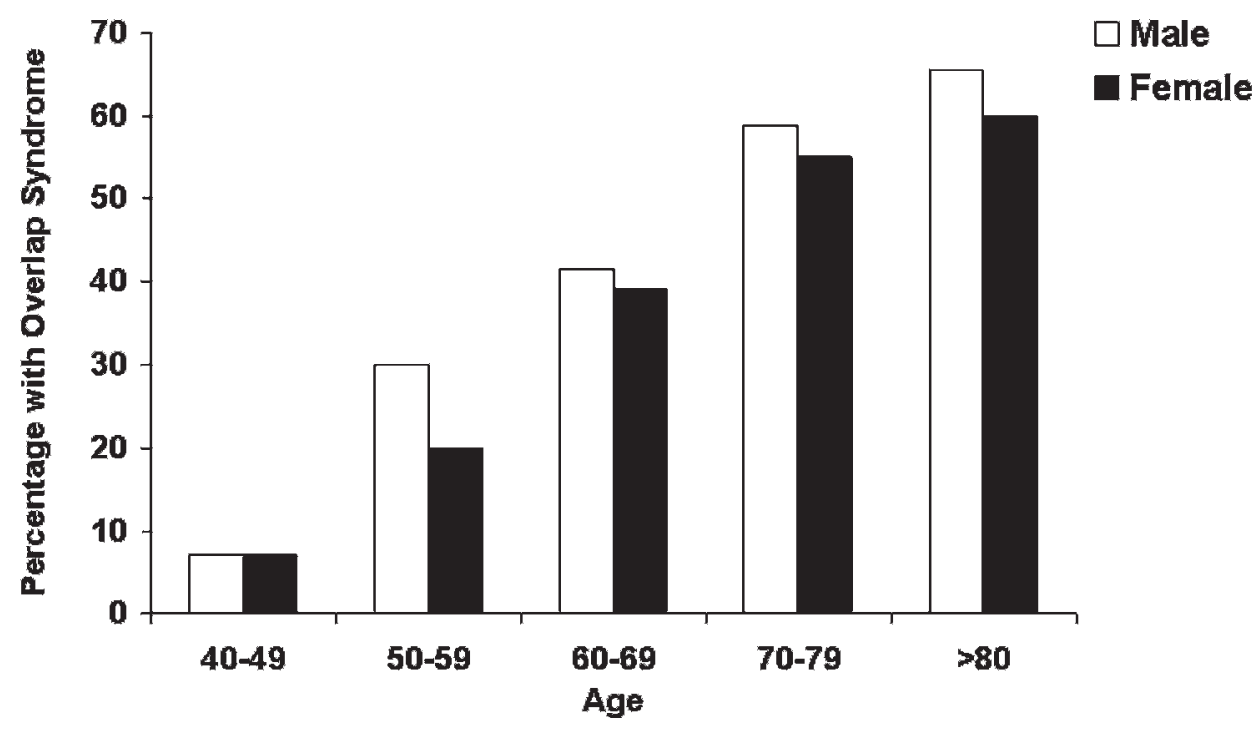

short label such as asthma and whether it provided a sufficient case description. ${ }^{\top}$

Thirdly, and perhaps more importantly, is that studying overlap syndrome may identify mechanistic pathways leading to the development of COPD. It is well known that patients with COPD typically present for care relatively late in the course of their disease, and that there is underdiagnosis of COPD in the community. By identifying common risk factors it may be possible to understand and modify the accelerated loss of lung function that leads to COPD. Several potentially important shared risk factors for overlapping asthma and COPD are increasing age, smoking, bronchial hyper-responsiveness (BHR) and exacerbations.

\section{CLINICAL RECOGNITION AND INFLAMMATORY FEATURES OF THE OVERLAP SYNDROME: WHAT IS IT?}

The clinical recognition of both asthma and COPD requires assessment of symptoms and physiological abnormalities (table 2). Symptoms can indicate the presence of a disease process; however, their sensitivity and specificity for asthma or COPD may be limited. At a physiological level, patients with overlap syndrome have evidence of incompletely reversible airflow obstruction (COPD) that can be detected by a reduced postbronchodilator $\mathrm{FEV}_{1}$ (fig 1). In addition, they have increased variability of airflow, which can be determined by increased bronchodilator responsiveness or BHR. The presence of airflow obstruction can confound the assessment of BHR in COPD. For recognition of the overlap syndrome, it may be preferable to use an indirect acting stimulus to assess BHR. Such agents do not

Table 2 Clinical and physiological characteristics of obstructive airway syndromes

\begin{tabular}{|c|c|c|c|c|}
\hline & Asthma & Overlap syndrome & COPD & Healthy \\
\hline Symptoms & + & + & + & - \\
\hline $\mathrm{FEV}_{1} / \mathrm{FVC}$ & $\geqslant 70 \%$ & $<70 \%$ & $<70 \%$ & $\geqslant 70 \%$ \\
\hline $\mathrm{FEV}_{1} \%$ predicted $^{*}$ & $>80 \%$ & $<80 \%$ & $<80 \%$ & $>80 \%$ \\
\hline $\mathrm{AHR}, \mathrm{PD}_{15} \dagger$ & $<12 \mathrm{ml}$ & $<12 \mathrm{ml}$ & $>12 \mathrm{ml}$ & $>12 \mathrm{ml}$ \\
\hline
\end{tabular}

\section{*Postbronchodilator}

$\uparrow \mathrm{PD}_{15}$, provocation dose of hypertonic saline that induces a $15 \%$ fall in $\mathrm{FEV}_{1}$ $A H R$, airway hyper-responsiveness; COPD, chronic obstructive pulmonary disease; $\mathrm{FEV}_{1}$, forced expiratory volume in $1 \mathrm{~s}$; FVC, forced vital capacity. directly cause airway smooth muscle contraction, and include hypertonic saline, adenosine and mannitol.

Informative data can be obtained from studies of discrete patient groups who have features of asthma and COPD. These groups include patients with asthma who smoke, those with asthma who develop incompletely reversible airflow obstruction and non-smokers who develop COPD. Smokers with asthma have features resembling COPD, since they are less responsive to corticosteroids and are less likely to have eosinophilic inflammation ${ }^{8}$ and more likely to have increased airway neutrophilia. ${ }^{9}$

The development of incompletely reversible airflow obstruction (COPD) is recognised to occur in some patients with longstanding asthma. ${ }^{11}{ }^{11}$ These patients tend to be older, male, with a longer duration of disease, and have an increased risk of death from airway disease. ${ }^{12}{ }^{13}$ A longitudinal study found that $16 \%$ of patients with asthma had developed incomplete airflow reversibility after $21-33$ years of follow-up. ${ }^{14}$ The pattern of inflammation associated with asthma and incomplete reversibility of airflow obstruction is heterogeneous. Studies that exclude smokers find evidence of eosinophilic inflammation from increased exhaled nitric oxide (NO), increased blood eosinophils ${ }^{12}$ and increased airway eosinophils. ${ }^{15}$ This design naturally excludes an important portion of the asthma population and permits a selection bias.

When unselected subjects with asthma and incomplete reversibility are studied, then there are increased airway neutrophils, with the intensity of neutrophilia correlated with the decline in $\mathrm{FEV}_{1} \cdot{ }^{16-18}$ We studied 44 older ( $>55$ years) adults with stable obstructive airway disease (asthma and/or COPD) to characterise the frequency of overlap syndrome, the pattern of airway complications and the pattern of airway inflammation. Sixty-five percent exhibited an overlap syndrome of asthma with COPD and only $16 \%$ and $21 \%$, respectively, could be definitively categorised as asthma and COPD using the criteria in table 2 . The participants with overlap syndrome and COPD were predominantly ex-smokers. Atopy was highest in asthma $(100 \%)$ whereas in overlap syndrome the rate of atopy was intermediate $(64 \%)$ between that of asthma and COPD alone $(25 \%)$. Airway complications in the overlap syndrome, such as the need for oral corticosteroids, and presence of chronic bronchitis and bacterial colonisation, resembled COPD rather 


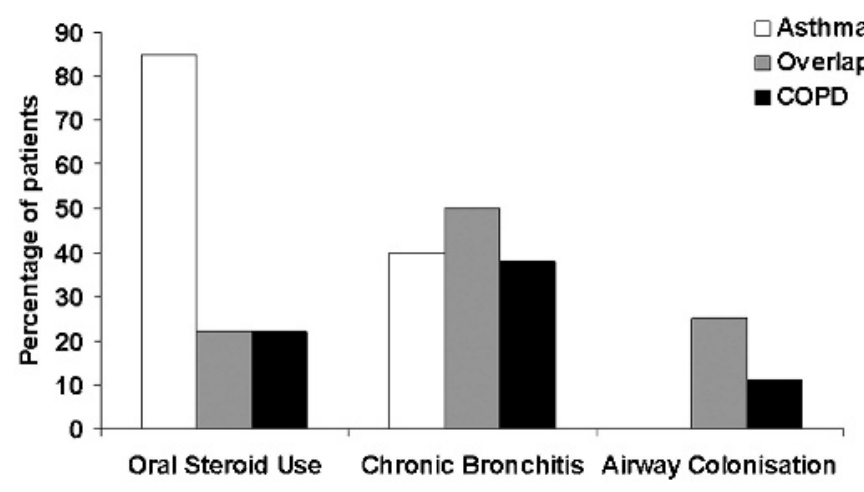

Figure 4 Airway complications and the overlap syndrome: percentage of patients with asthma (white bars), chronic obstructive pulmonary disease (COPD) (black bars) and overlap syndrome (grey bars) requiring oral corticosteroids for an exacerbation in the past year, with chronic bronchitis and with airway colonisation with bacteria.

than asthma (fig 4). Sputum neutrophils and total cells were highest in those with overlap syndrome, where absolute numbers of neutrophils were up to five times higher than those with asthma alone and older healthy controls (fig 5A). Eosinophil numbers were significantly increased in those with asthma compared with healthy controls but not different between the groups with airway disease (fig 5B). Together these data confirm that the overlap syndrome of asthma and COPD is common in older people, has intermediate risk factor prevalence, but resembles COPD in terms of airway complications and the pattern of airway inflammation with increased airway neutrophils.

\section{Airway remodelling and the overlap syndrome}

There is also increased airway wall remodelling in the overlap syndrome, with increased bronchial wall thickening on high resolution CT (HRCT). ${ }^{12}$ Increased thickness of the airway wall is an important feature leading to airway obstruction in most airway diseases. ${ }^{19} 20$ In asthma, this is due to inflammation, subepithelial fibrosis and increased thickness of the smooth muscle. ${ }^{21}$ There is also increased thickness of the airway wall in COPD, which is not as prominent as in asthma, ${ }^{22}$ but involves the same structures of the epithelium, reticular basement membrane, airway smooth muscle and mucous glands. There is also evidence of remodelling, fibrosis and inflammation in these structures. ${ }^{23}{ }^{24}$ The increased smooth muscle reported in COPD is seen in some $e^{25}$ but not all studies. Increased thickness of the airway epithelium and goblet cell hyperplasia are features of the remodelled airway in both asthma and COPD. Similarly, increased airway wall fibrosis is reported in both asthma and COPD. ${ }^{23} 2426$ Thus when considering the pathological changes within the airways that are associated with asthma and COPD, there is similarity in terms of structures that are remodelled, but differences in the degree of changes in specific structures. ${ }^{12}$

\section{WHY IS THERE OVERLAP? WHY DOES IT OCCUR?}

Overlapping asthma and COPD could occur for several reasons. Asthma and COPD are two common conditions, and by chance alone there will be overlap. The two conditions may also share common risk factors or origins, which means that one may evolve into the other. One expression of this possibility, the "Dutch hypothesis", was proposed by Orie who suggested that BHR may be a risk factor for asthma and COPD. ${ }^{2}$ Another expression of the common risk hypothesis for overlap syndrome

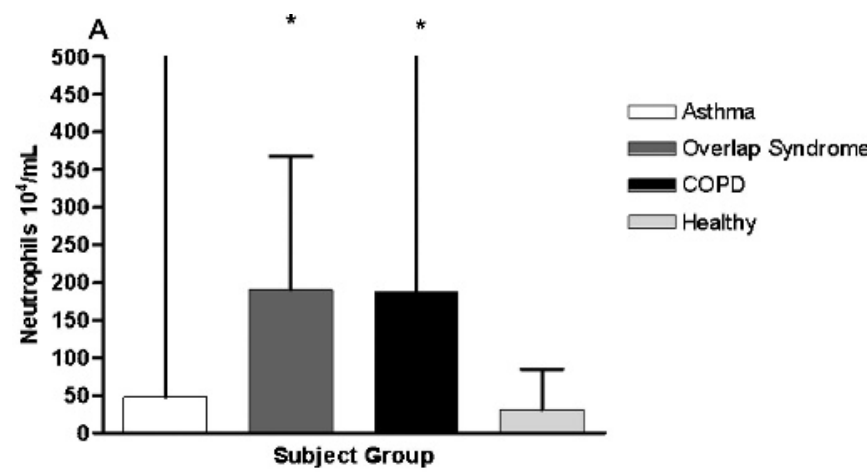

B
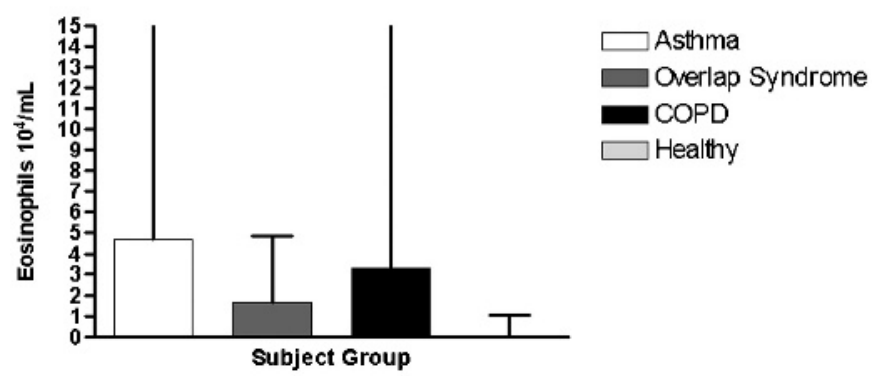

Figure 5 (A) Number $\left(\times 10^{4} / \mathrm{ml}\right)$ of sputum neutrophils in the airways of adults with asthma (white bars), chronic obstructive pulmonary disease (COPD) (black bars), overlap syndrome (dark grey bars) and healthy controls (light grey bars). ${ }^{*} p<0.004$ vs healthy controls. (B) Number $\left(\times 10^{4} / \mathrm{ml}\right)$ of sputum eosinophils in the airways of participants with asthma (white bars), COPD (black bars), overlap syndrome (dark grey bars) and healthy controls (light grey bars). ${ }^{*} \mathrm{p}<0.004$ vs healthy controls.

comes from the study of childhood diseases. Epidemiological studies have identified an association between childhood respiratory illness and impaired adult lung function. ${ }^{27}$ Airway growth starts in utero and continues throughout childhood into early adult years. Any diseases or exposures that lead to incomplete airway growth may also contribute to impaired

\section{Pathways to chronic obstructive pulmonary disease (COPD)}

Pathways to COPD

- Accelerated decline in adult lung function

- Incomplete lung growth during childhood

- Common risk factors

- Smoking

- Bronchial hyper-responsiveness

- Asthma

- Exacerbation/infection

- Risk factor potentiation

- Asthma

- Bronchial hyper-responsiveness

- Smoking

- Exacerbations

- Other relevant risk factors

- Gender

- Body weight

- Susceptibility genes 
Figure 6 Forced expiratory volume in $1 \mathrm{~s}\left(\mathrm{FEV}_{1}\right) \mathrm{ml}$ (corrected for height, weight and age at first survey) for males: non-smoking males without asthma (continuous line), non-smoking with asthma (dotted line), smoking without asthma (dashed and dotted line) and smoking with asthma (dashed line). (Reproduced with permission from the American Journal of Respiratory and Critical Care Medicine).

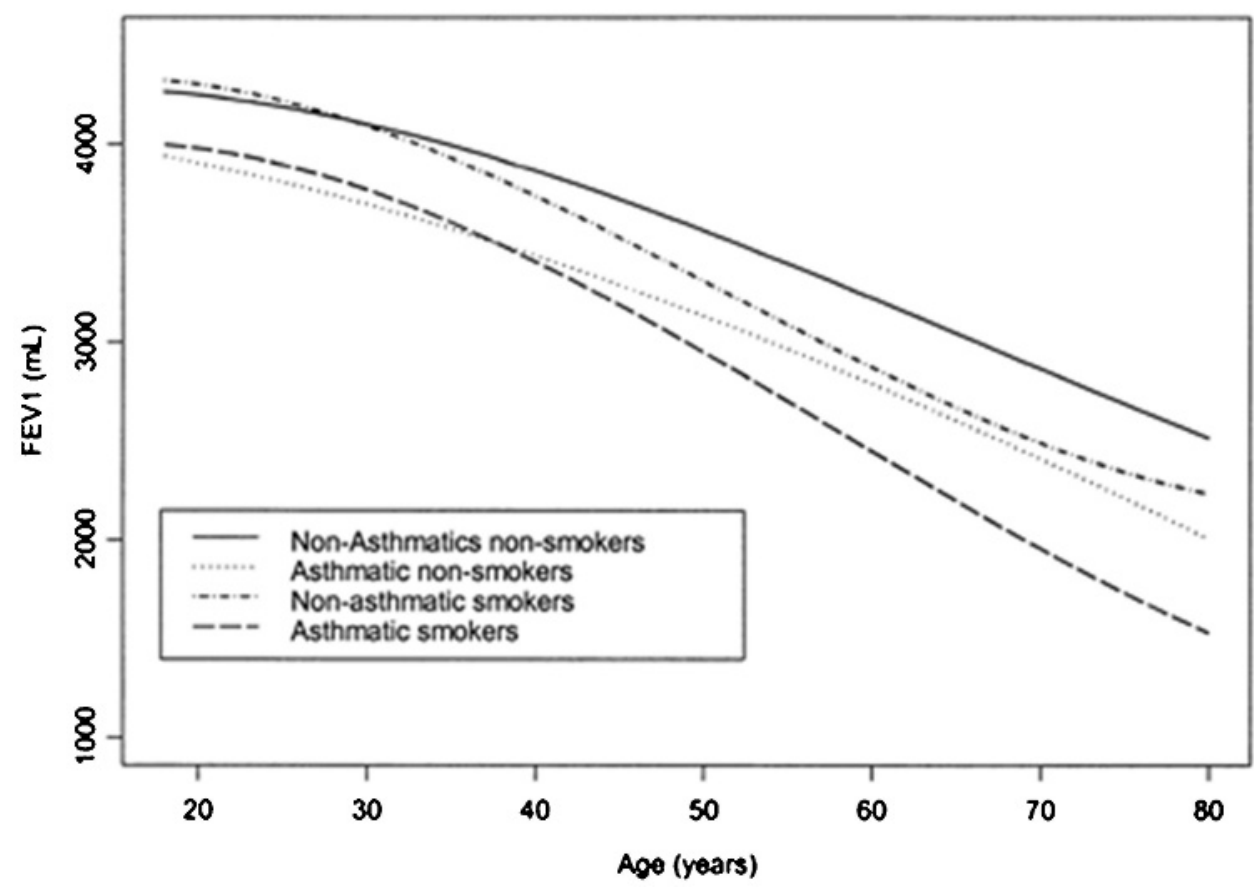

adult lung function. In this way, fetal or childhood exposures may contribute to adult asthma and COPD. ${ }^{28}$

Adult COPD may therefore result from accelerated decline in lung function, failure to attain maximal airway growth or a combination of the two (box 1). An examination of lung growth through life shows evidence for both of these circumstances (fig 6). Identification of risk factors for these events will aid understanding of COPD and suggest ways to prevent the onset of COPD. Remodelling of airway structural elements is a key factor in airway growth, and is now recognised to be an important part of the pathological processes involved in asthma and COPD. ${ }^{21}$ This suggests that there will be overlap or commonality in the risk factors for impaired lung growth and accelerated decline in airway function. Epidemiological studies have shown this to be the case. Unexpectedly, there also appears to be risk factor potentiation, where each of the more common risk factors interacts with one or more other risk factors to potentiate the development of COPD. For example, smoking and asthma are independent risk factors for COPD, and smoking itself is a risk factor for asthma. Predictably, when the risks of combined asthma and smoking are examined, then the effects accumulate, and decline in adult lung function in smokers with asthma is greater than in asthma or smokers alone. ${ }^{129}$

\section{Accelerated decline in lung function}

Since COPD represents incomplete reversibility of airflow obstruction, then any risk factor that leads to accelerated loss of lung function will contribute to the development of COPD. Several risk factors for accelerated decline in include age, smoking, BHR, asthma and exacerbations or lower respiratory infections. Increasing age is associated with decline in lung function, both in asthma and in those without asthma. ${ }^{1}{ }^{29}$

\section{Smoking}

Loss of lung function is accelerated by smoking by up to $50 \mathrm{ml}$ per year, ${ }^{29}{ }^{30}$ and there is an established dose-response relationship. ${ }^{29}{ }^{32}$ The loss of lung function with smoking may even be greater in those with asthma, such that smokers with asthma can develop COPD. Importantly, quitting smoking slows the decline in lung function. In the Lung Health Study, the annual decline in $\mathrm{FEV}_{1}$ in people who quit smoking at the beginning of the 11 year study was $30 \mathrm{ml} /$ year for men and $22 \mathrm{ml} /$ year for women. Continued smoking led to a decline in $\mathrm{FEV}_{1}$ of $66 \mathrm{ml} /$ year in men and $52 \mathrm{ml} /$ year in women. ${ }^{30}$

\section{Bronchial hyper-responsiveness}

BHR is present in between $10 \%$ and $20 \%$ of the population, and is frequently asymptomatic. ${ }^{23}$ The role of asymptomatic BHR in the development of asthma and COPD was investigated in the SAPALDIA (Study on Air Pollution and Lung Diseases in Adults) study. At baseline, $17 \%$ of the population had BHR to methacholine, and $50 \%$ of these were asymptomatic, giving a prevalence of asymptomatic BHR of $9 \%$. Asymptomatic BHR was associated with an increased risk of developing newly diagnosed asthma, new symptoms of wheeze, chronic cough and a diagnosis of COPD after a 11 year follow-up period (table 3). ${ }^{34}$ Smoking led to an increased risk of developing BHR. ${ }^{35}{ }^{36}$ This is an example of risk factor potentiation, where one risk for COPD positively interacts with another to potentiate the COPD risk.

BHR was also associated with an accelerated decline in lung function, and there was a significant interaction with smoking. There was a mean additional decline in $\mathrm{FEV}_{1}$ of $12 \mathrm{ml} /$ year in current smokers and $11 \mathrm{ml} /$ year in former smokers with BHR. Never-smokers with BHR also had an accelerated decline of $4 \mathrm{ml} /$ year compared with asymptomatic participants without $\mathrm{BHR}$. Thus active smokers with BHR were particularly at risk for the development of COPD. The mechanism is not known but may involve airway inflammation since induced sputum inflammatory markers were found to be increased in smokers with BHR. ${ }^{37}$

\section{Asthma}

Several epidemiological studies have identified that there is accelerated decline in lung function as a result of asthma and 
Table 3 Risk for the development of respiratory symptoms and for the presence of chronic obstructive pulmonary disease (COPD) related to asymptomatic bronchial hyper-responsiveness (BHR) ${ }^{34}$

\begin{tabular}{lll}
\hline & Adjusted OR $\mathbf{~ 9 5 \% ~} \mathbf{C l})$ & $\mathbf{p}$ Value \\
\hline $\begin{array}{l}\text { Asthma phenotypes } \\
\begin{array}{l}\text { Physician-diagnosed } \\
\text { asthma }\end{array}\end{array}$ & $3.0(1.8$ to 5.0$)$ & 0.001 \\
$\begin{array}{l}\text { Wheeze in last } 12 \text { months } \\
\text { without cold }\end{array}$ & $2.9(1.8$ to 4.5$)$ & 0.001 \\
$\begin{array}{l}\text { Shortness of breath while } \\
\text { walking }\end{array}$ & $1.3(0.9$ to 1.8$)$ & 0.115 \\
COPD phenotypes & & \\
All participants & & \\
Chronic phlegm & $1.2(0.7$ to 2.0$)$ & 0.478 \\
Chronic cough & $3.0(1.7$ to 5.2$)$ & 0.001 \\
Chronic bronchitis* & $2.6(1.1$ to 6.0$)$ & 0.023 \\
COPD $\dagger$ & $4.5(3.3$ to 6.0$)$ & 0.001 \\
\hline
\end{tabular}

Reproduced with permission from Thorax.

${ }^{*}$ Chronic bronchitis was defined as the presence of chronic cough or phlegm. $\dagger \mathrm{COPD}$ was defined as forced expiratory volume in $1 \mathrm{~s}\left(\mathrm{FEV}_{1}\right) /$ forced vital capavity $(\mathrm{FVC})<0.70$ and no physician's diagnosis of asthma.

this positively interacts with smoking. The factors associated with accelerated lung function decline in asthma include more severe $\mathrm{BHR},{ }^{38}$ adult-onset asthma, ${ }^{39}$ frequent severe exacerbations ${ }^{40}$ persistent symptoms, ${ }^{41}$ baseline airflow obstruction ${ }^{38}$ and persistent elevation of exhaled $\mathrm{NO}$ in difficult to treat asthma. ${ }^{42}$ There is clear evidence of risk factor potentiation, as many of the risks for accelerated lung function decline in asthma are also risk factors for lung function decline themselves-that is, smoking, BHR and severe exacerbations. Interestingly, baseline airflow obstruction, which is a risk for accelerated lung function decline, may result from incomplete lung growth as a result of childhood asthma or other childhood exposures, and is an example where the pathways to COPD (box 1) potentiate each other.

The deficits in lung function in asthma seem to arise early in the course of the disease, ${ }^{43}{ }^{44}$ and may be an effect of incomplete lung growth. ${ }^{43}$ In one study, abnormal lung function at age 26 in patients with asthma was related to male sex, BHR at age 9 years, early onset of asthma and reduced lung function by age 9 years. ${ }^{41}$

\section{Exacerbations}

Both patients with asthma and those with COPD experience exacerbations of their disease. These are clinically significant events, frequently triggered by viral respiratory tract infection, and associated with quality of life impairment, loss of functional ability and increased healthcare utilisation. Recent data now show that disease exacerbations in both asthma and $\mathrm{COPD}^{45}{ }^{46}$ (fig 7) can lead to accelerated loss of lung function. In asthma a longitudinal cohort study of patients with persistent asthma ${ }^{14}$ found a greater decline in $\mathrm{FEV}_{1}$ in those patients with frequent severe exacerbations. In a regression analysis, one severe exacerbation was associated with a $30 \mathrm{ml}$ greater annual decline in $\mathrm{FEV}_{1}$. These results show that a severe asthma exacerbation is associated with accelerated $\mathrm{FEV}_{1}$ decline, to a similar degree as that seen with smoking and COPD. Another important observation was that the decline in $\mathrm{FEV}_{1}$ seen in infrequent exacerbators was not different from the population without asthma. This raises the possibility that modifying the exacerbation rate may prevent the onset of fixed airflow obstruction in asthma.

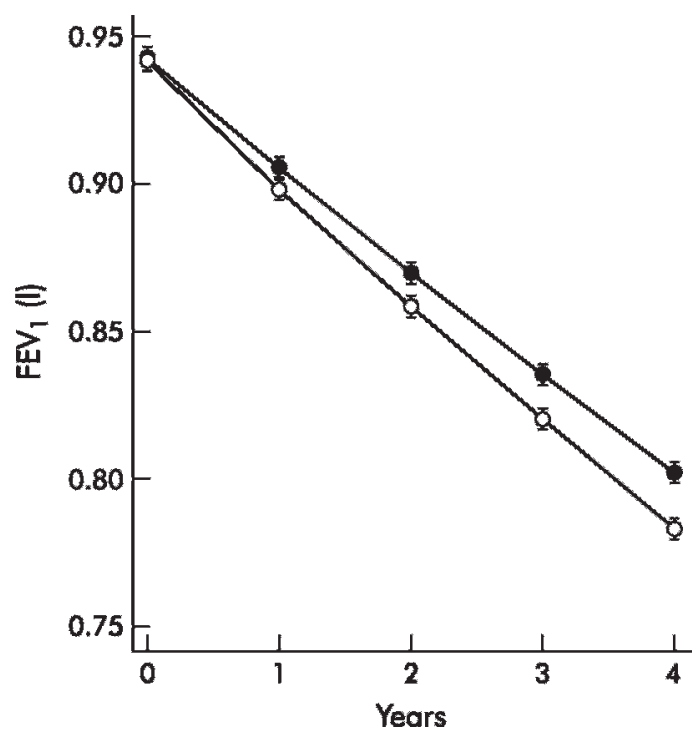

Figure 7 Annual change in forced expiratory volume in $1 \mathrm{~s}\left(\mathrm{FEV}_{1}\right)$ for patients with frequent (filled circles) and infrequent (open circles) exacerbations of chronic obstructive pulmonary disease (COPD). (Reproduced with permission from Thorax).

\section{Childhood: risk factors for incomplete lung growth}

Lung function in early adult life is a strong risk factor for the development of COPD. There is now evidence that poor lung function in infancy and childhood persists into adulthood, and that in utero events can modify airway function in early postnatal life. Stern et al studied lung function in infants soon after birth and found that poor airway function at that time was a risk factor for impaired adult lung function, ${ }^{45}$ suggesting that airway function throughout adult life may be determined during fetal development and the first few months of postnatal life. ${ }^{45}$ Maternal smoking adversely influences lung growth. ${ }^{46}$ In infancy there is an $\sim 15-20 \%$ reduction in airflow in children born to mothers who smoked during pregnancy. ${ }^{47}$ In addition, maternal smoking is associated with impaired fetal growth, and intrauterine growth retardation is itself associated with impaired airway function in infancy and later life.

Many of the risk factors for incomplete lung growth in childhood are similar to the risk factors for accelerated loss of lung function in adults, namely tobacco smoke exposure, asthma, $\mathrm{BHR}^{48}$ and exacerbations or respiratory infections. Additional risk factors include low birth weight, gender (lower in boys), nutrition and ethnicity.

\section{Asthma}

Several longitudinal studies show that at the commencement of adulthood, lung function is lower in people with asthma than in those without (fig 6). ${ }^{29} 4143$ Impaired lung function has been observed in up to $25 \%$ of children in the Childhood Asthma Management Program ${ }^{49}$ and in children with eosinophilic asthma. ${ }^{52}$ This suggests that there may be incomplete lung growth with asthma, and this can be another pathway to the development of impaired lung function in adulthood.

There is an established relationship between smoking and asthma, with smoking potentiating the effects of asthma on respiratory ill-health. Surprisingly, there appears to be bidirectionality in the relationship between smoking and asthma. Studies have shown unexpectedly higher smoking rates in some groups with asthma, such as adolescents and pregnant women. 
Longitudinal studies among adolescents have identified that asthma is a risk factor for starting smoking and becoming a regular smoker..$^{50}$

\section{Early life infections}

There is emerging evidence of a role for early life infections leading to impaired lung function and modification of asthma risk. For example, Barker studied lung function in adult men and found an association between respiratory infection during infancy and reduced adult lung function. ${ }^{51}$ Other studies show that respiratory viral infection modifies BHR, which is a risk for impaired lung function. Of equal importance is the now wellestablished observation that impaired lung function often precedes a viral-induced wheezing illness in childhood and leads to an increased likelihood of wheezing when a child subsequently develops a respiratory infection. ${ }^{52}$ This suggests a complex relationship between childhood respiratory infection and subsequent lung growth, and the need for more detailed mechanistic studies.

These events can be studied successfully in dynamic model systems. Chlamydia infection has been associated with asthma and may both cause acute infection and then enter a state of persistent infection with episodic reactivation. ${ }^{53}$ Chlamydia infection is also prevalent, and exposure can occur not only via respiratory infection, but during birth infants could be exposed to maternal Chlamydia, leading to the potential for early life Chlamydia exposure. When the effects of neonatal Chlamydia infection are examined in models of allergic sensitisation, then profound changes are seen. Neonatal Chlamydia infection leads to impaired lung growth with abnormal airspace enlargement. When combined with allergic sensitisation, then adult BHR is enhanced by neonatal Chlamydia infection, and there is enhanced airway remodelling with increased airway goblet cells, and abnormal airspace enlargement. ${ }^{53}$

\section{CONCLUSION}

Older people with symptomatic obstructive airways disease frequently have overlapping features of variable airflow obstruction (asthma) and incompletely reversible airflow limitation (COPD). They may have a prominent neutrophilic bronchitis and experience mucus hypersecretion. The overlap syndrome can occur due to accelerated decline in lung function and incomplete lung growth in children. These pathways share common risk factors of tobacco smoke exposure, BHR, asthma and respiratory infections. These risk factors may in turn cooccur and potentiate each other. In studying the pathogenesis of overlap syndrome, it will be fruitful to look for mediators that drive both airway inflammation and airway remodelling. Since patients with overlap syndrome are usually excluded from randomised treatment trials, the recommendations for management are necessarily extrapolated from trials of asthma alone or COPD alone. There is a need to extend drug efficacy studies to include patients with overlapping asthma and COPD, and address the many research opportunities to investigate the mechanisms and treatment of overlapping asthma and COPD in older people.

Funding: PGG holds an NHMRC Practitioner Fellowship and JLS holds am NHMRC Centre of Respiratory Research Excellence Fellowship.

Competing interests: None.

\section{REFERENCES}

1. Lange $\mathbf{P}$, Parner J, Vestbo J, et al. A 15 year follow-up study of ventilatory function in adults with asthma. N Engl J Med 1998;339:1194-2000.
2. Vestbo J, Prescott E. Update on the "Dutch hypothesis" for chronic respiratory disease. Thorax 1998;53:S15-9.

3. American Thoracic Society. Standards for diagnosis and care of patients with chronic obstructive pulmonary disease. Am J Respir Crit Care Med 1995;152:s77-121.

4. Soriano JB, Davis KJ, Coleman B, et al. The proportional Venn diagram of obstructive lung disease: two approximations from the United States and the United Kingdom. Chest 2003;124:474-81.

5. Marsh SE, Travers J, Weatherall M, et al. Proportional classifications of COPD phenotypes. Thorax 2008;63:761-7.

6. Chaudhuri R, Livingston $\mathrm{E}, \mathrm{McMahon} \mathrm{AD}$, et al. Cigarette smoking impairs the therapeutic response to oral corticosteroids in chronic asthma. Am J Respir Crit Care Med 2003;168:1308-11

7. Pride NB, Vermeire P, Allegra L. Diagnostic labels applied to model case histories of chronic airflow obstruction. Responses to a questionnaire in 11 North American and Western European countries. Eur Resp J 1989;2:702-9.

8. Chalmers GW, MacLeod KJ, Thomson L, et al. Smoking and airway inflammation in patients with mild asthma. Chest 2001;120:1917-22.

9. Boulet LP, Lemiere C, Archambault $F$, et al. Smoking and asthma: clinical and radiologic features, lung function, and airway inflammation. Chest 2006;129:661-8.

10. Brown PJ, Greville HW, Finucane KE. Asthma and irreversible airflow obstruction. Thorax 1984;39:131-6.

11. Backman KS, Greenberger PA, Patterson R. Airways obstruction in patients with long-term asthma consistent with "irreversible asthma". Chest 1997;112:1234-40.

12. Bumbacea D, Campbell D, Nguyen L, et al. Parameters associated with persistent airflow obstruction in chronic severe asthma. Eur Resp J 2004;24:122-8.

13. Panizza JA, James AL, Ryan G, et al. Mortality and airflow obstruction in asthma: a 17-year follow-up study. Intern Med J 2006;36:773-80.

14. Vonk JM, Jongepier H, Panhuysen CIM, et al. Risk factors associated with the presence of irreversible airflow limitation and reduced transfer coefficient in patients with asthma after 26 years of follow up. Thorax 2003;58:322-7.

15. Fabbri LM, Romagnoli M, Corbetta $\mathrm{L}$, et al. Differences in airway inflammation in patients with fixed airflow obstruction due to asthma or chronic obstructive pulmonary disease. Am J Respir Crit Care Med 2003;167:418-24.

16. Boulet $\mathbf{L P}$, Turcotte $\mathrm{H}$, Turcot 0 , et al. Airway inflammation in asthma with incomplete reversibility of airflow obstruction. Respir Med 2003;97:739-44.

17. Shaw DE, Berry MA, Hargadon B, et al. Association between neutrophilic airway inflammation and airflow limitation in adults with asthma. Chest 2007;132:1871-5.

18. Jang AS, Lee JH, Park SW, et al. Risk factors related to fixed airway obstruction in patients with asthma after antiasthma treatment. Ann Allergy Asthma Immunol 2007;99:408-12.

19. Roberts HR, Wells AU, Milne DG, et al. Airflow obstruction in bronchiectasis: correlation between computed tomography features and pulmonary function tests. Thorax 2000;55:198-204.

20. Park JW, Hong YK, Kim CW, et al. High resolution computed tomography in patients with bronchial asthma: correlation with clinical features, pulmonary function and bronchial hyperresponsiveness. J Investig Allergol Clin Immunol 1997;7:186-92.

21. James AL, Wenzel SE. Clinical relevance of airway remodelling in airway diseases. Eur Resp J 2007;30:134-55.

22. Bosken $\mathbf{C H}$, Wiggs BR, Pare PD, et al. Small airway dimensions in smokers with obstruction to airflow. Am Rev Respir Dis 1990;142:563-70.

23. Nagai $\mathbf{A}$, West WW. Thurlbeck WM. The National Institutes of Health Intermittent Positive-Pressure Breathing Trial: pathology studies. II. Correlation between morphologic findings, clinical findings and evidence of expiratory air-flow obstruction. Am Rev Respir Dis 1985;132:946-53.

24. Wright JL, Lawson LM, Pare PD, et al. Morphology of peripheral airways in current smokers and ex-smokers. Am Rev Respir Dis 1983;127:474-7.

25. Hogg JC, Chu F, Utokaparch S, et al. The nature of small-airway obstruction in chronic obstructive pulmonary disease. N Engl J Med 2004;350:2645-53.

26. Cosio M, Ghezzo H, Hogg JC, et al. The relations between structural changes in small airways and pulmonary-function tests. N Engl J Med 1978;298:1277-81.

27. Burrows B, Knudson R, Lebowitz M. The relationship of childhood respiratory illness to adult obstructive airway disease. Am Rev Respir Dis 1977;115:51-60.

28. Stick S. The contribution of airway development to paediatric and adult lung disease. Thorax 2000;55:587-94.

29. James AL, Palmer LJ, Kicic E, et al. Decline in lung function in the Busselton Health Study. Am J Respir Crit Care Med 2005;171:109-14.

30. Anthonisen NR, Connett JE, Murray RP. Smoking and lung function of Lung Health Study participants after 11 years. Am J Respir Crit Care Med 2002;166:675-9.

31. Lindberg A, Jonsson AC, Rönmark E, et al. Ten-year cumulative incidence of COPD and risk factors for incident disease in a symptomatic cohort. Chest 2005; 127:1544-52.

32. Lokke A, Lange P, Scharling H, et al. Developing COPD: a 25 year follow up study of the general population. Thorax 2006;61:935-9.

33. $\mathbf{X u} \mathbf{X}$, Rijcken B, Schouten JP, et al. Airways responsiveness and development and remission of chronic respiratory symptoms in adults. Lancet 1997;350:1431-4.

34. Brutsche MH, Downs SH, Schindler C, et al. Bronchial hyperresponsiveness and the development of asthma and COPD in asymptomatic individuals: SAPALDIA Cohort Study. Thorax 2006:61:671-7.

35. Rijcken B, Schouten JP, Mensinga TT, et al. Factors associated with bronchial responsiveness to histamine in a population sample of adults. Am Rev Respir Dis 1993;147:1447-53. 
36. Chinn S, Jarvis D, Luczynska CM, et al. An increase in bronchial responsiveness is associated with continuing or restarting smoking. Am J Respir Crit Care Med 2005; 172:156-61.

37. Betz R, Kohlhäufl M, Kassner G, et al. Increased sputum IL-8 and IL-5 in asymptomatic nonspecific airway hyperresponsiveness. Lung 2001;179:119-33.

38. Peat JK, Woolcock AJ, Cullen K. Rate of decline of lung function in subjects with asthma. Eur J Respir Dis 1987;70:171-9.

39. ten Brinke A, Zwinderman AH, Sterk PJ, et al. Factors associated with persistent airflow limitation in severe asthma. Am J Respir Crit Care Med 2001;164:744-8.

40. Bai TR, Vonk JM, Postma DS, et al. Severe exacerbations predict excess lung function decline in asthma. Eur Resp J 2007;30:452-6.

41. Sears MR, Greene JM, Willan AR, et al. A longitudinal, population-based, cohort study of childhood asthma followed by adulthood. N Engl J Med 2003;349:1414-22.

42. van Veen IH, Ten Brinke A, Sterk PJ, et al. Exhaled nitric oxide predicts lung function decline in difficult-to-treat asthma. Eur Resp J 2008:32:344-9.

43. Rasmussen F, Taylor DR, Flannery EM, et al. Risk factors for airway remodeling in asthma manifested by a low postbronchodilator $\mathrm{FEV}_{1} /$ vital capacity ratio: a longitudinal population study from childhood to adulthood. Am J Respir Crit Care Med 2002;165:1480-8.

44. Phelan PD, Robertson CF, Olinsky A. The Melbourne Asthma Study: 1964-1999. J Allergy Clin Immunol 2002;109:189-94.

45. Stern DA, Morgan WJ, Wright AL, et al. Poor airway function among preterm infants whose mothers smoked during pregnancy. Am J Respir Crit Care Med 2007:158:700-5.
46. Stein RT, Holberg CJ, Sherrill D, et al. Influence of parental smoking on respiratory symptoms during the first decade of life. Am J Epidemio 1999; 149:1030-7

47. Wright AL, Holberg C, Martinez FD, et al. Relationship of parental smoking to wheezing and nonwheezing lower respiratory tract illness in infancy. J Pediatr 1991;118:207-14.

48. Palmer LJ, Rye PJ, Gibson NA, et al. Airway responsiveness in early infancy predicts asthma, lung function, and respiratory symptoms by school age. Am J Respir Crit Care Med 2001;163:37-42.

49. Covar RA, Spahn JD, Murphy JR, et al. Progression of asthma measured by lung function in the childhood asthma management program. Am J Respir Crit Care Med 2004;170:234-41.

50. Van De Ven MO, Engels RC, Sawyer SM. Asthma-specific predictors of smoking onset in adolescents with asthma: a longitudinal study. J Pediatr Psychol 2009;34:118-28.

51. Barker DJ, Godfrey KM, Fall C, et al. Relation of birth weight and childhood respiratory infection to adult lung function and death from chronic obstructive airways disease. BMJ 1991:303:671-5.

52. Martinez FD, Morgan WJ, Wright AL, et al. Diminished lung function as a predisposing factor for wheezing respiratory illness in infants. N Engl J Med 1988;319:1112-7.

53. Horvat JC, Beagley KW, Wade MA, et al. Neonatal chlamydial infection induces mixed T-cell responses that drive allergic airway disease. Am J Respir Crit Care Med 2007:176:556-64.

\section{Which COPD patients should be admitted to the ICU?}

A total of 832 patients with obstructive lung disease aged 45 years and older were prospectively recruited from 92 intensive care units and 3 respiratory high-dependency units in the UK. Detailed physiological and functional data were collected on admission to intensive care and they were followed up for 180 days.

Mortality at 180 days was $37.9 \%$. A scoring system was created from the data in order to predict mortality. The score uses the presence of the following parameters to predict poor outcome (in order of importance): abnormal acute physiology, poor functional status (bed or chair bound, house bound or restricted), atrial fibrillation, male sex, number of days in hospital before intensive care admission, reduced midarm circumference as a measure of nutrition and muscle mass, years of age over 70 and reduced Glasgow Coma Score. The COPD acute physiology score contains heart rate, mean arterial pressure, $\mathrm{pH}$, sodium, urea, creatinine, albumin and white cell count. The score was found to be superior to the clinical judgement of participating clinicians.

The score could be used to support clinical reasoning prior to ICU admission of patients with COPD and put decision-making in this often underprivileged group on a more rational footing. Additionally, the scoring model could help risk adjustment for audit and research across different hospitals.

Results previously published from this study show that a large majority of patients with COPD achieve acceptable quality of life following their stay in the intensive care unit and would want to be readmitted under similar circumstances. This paper suggests that more should be done to help to get them this chance.

- Wildman MJ, Sanderson C, Groves J, et al. Predicting mortality for patients with exacerbations of COPD and asthma in the COPD and Asthma Outcome Study (CAOS). OJM 2009;102:389-99.

\section{Subbe}

Correspondence to: Dr C Subbe, Department of Acute, Respiratory and Intensive Care Medicine, Wrexham Maelor Hospital, Wrexham, UK; csubbe@hotmail.com 